\title{
Mental Illness and/or Mental Health? Investigating Axioms of the Complete State Model of Health
}

\author{
Corey L. M. Keyes \\ Emory University
}

\begin{abstract}
A continuous assessment and a categorical diagnosis of the presence (i.e., flourishing) and the absence (i.e., languishing) of mental health were proposed and applied to the Midlife in the United States study data, a nationally representative sample of adults between the ages of 25 and 74 years $(N=3,032)$. Confirmatory factor analyses supported the hypothesis that measures of mental health (i.e., emotional, psychological, and social well-being) and mental illness (i.e., major depressive episode, generalized anxiety, panic disorder, and alcohol dependence) constitute separate correlated unipolar dimensions. The categorical diagnosis yielded an estimate of $18.0 \%$ flourishing and, when cross-tabulated with the mental disorders, an estimate of $16.6 \%$ with complete mental health. Completely mentally healthy adults reported the fewest health limitations of activities of daily living, the fewest missed days of work, the fewest half-day work cutbacks, and the healthiest psychosocial functioning (low helplessness, clear life goals, high resilience, and high intimacy).
\end{abstract}

Keywords: subjective well-being, happiness, depression, mental health, mental illness, mental disorder, psychopathology

Health is not simply the absence of disease: it is something positive. . . - Henry Sigerist, Medicine and Human Welfare

There exists no standard by which to measure, diagnose, and study the presence of mental health; science, by default, portrays mental health as the absence of psychopathology. This study introduces self-report measures of mental health for use in the general population that may also be useful with clinical patients. It summarizes the scales and dimensions of subjective well-beingthe evaluations and declarations that individuals make about the quality of their lives - that are used as measures of the symptoms of mental health. Mental health is conceived of as a complete state in which individuals are free of psychopathology and flourishing (Keyes, 2002, 2003a, 2003b) with high levels of emotional, psychological, and social well-being.

Because of skepticism of the benefits of studying mental health, there are to my knowledge literally no studies of the latent structure or the use of regarding mental health as more than the absence of psychopathology. In this study, I investigate two axioms of the complete state model of health. First, rather than forming a single bipolar dimension, health and illness are correlated unipolar dimensions that, together, form a complete state of (mental) health. Second, the presence of mental health is presumed to be the summum bonum of personal functioning and social value. In this

Corey L. M. Keyes, Department of Sociology and Department of Behavioral Sciences and Health Education of the Rollins School of Public Health, Emory University.

This research was supported by membership in the John D. and Catherine T. MacArthur Foundation Research Network on Successful Midlife Development (Director: Orville Gilbert Brim).

Correspondence concerning this article should be addressed to Corey L. M. Keyes, Emory University, Room 225 Tarbutton Hall, 1555 Dickey Drive, Atlanta, GA 30322. E-mail: corey.keyes@emory.edu study, I examine three descriptive questions to investigate the use of the mental health diagnosis. What is the point prevalence of mental health (i.e., flourishing) and of complete mental health (i.e., flourishing and free of 12-month mental disorder)? Does the risk of Diagnostic and Statistical Manual of Mental Disorders (3rd ed., rev.; DSM-III-R; American Psychiatric Association, 1987) 12month mental disorders decrease as mental health increases? Does psychosocial functioning (e.g., perceived helplessness) improve as the level of mental health increases?

\section{Health or Illness? Health and Illness?}

Health has been alleged to be a complete state consisting of not merely the absence of illness but the presence of something positive (Ryff \& Singer, 1998; Sigerist, 1941; World Health Organization, 1948). The de facto conception of mental health is psychiatric: Individuals are either mentally ill or presumed mentally healthy. This position rests on the untested assumption that measures of mental illness and health form a single bipolar dimension. Several reasons justify the primacy of the dichotomous, psychiatric view of mental health. First, at the birth of the National Institute of Mental Health, the field of psychopathology was better developed empirically than the mostly theoretical literature of clinical and personality psychology that informed conceptions of positive mental health (Jahoda, 1958; Smith, 1959). Second, evidence is now overwhelming that individuals free of major depression, for example, function better and are more productive than depressed individuals (Sartorius, 2001). Third, evidence is indisputable that mental illness is a serious public health issue. Mental disorders are prevalent (often comorbid), recur throughout the life span, are costly to treat, and cause premature mortality when untreated (Garrison, Schluchter, Schoenbach, \& Kaplan, 1989; Greenberg, Stiglin, Finkelstein, \& Berndt, 1993; Kessler et al., 1994; Keyes \& Lopez, 2002; U.S. Public Health Service, 1998, 1999). 
The burden of mental illness now deflects attention from the question and significance of mental health. However, mental health remains a nascent public health issue, because the vast majority of the U.S. population is free of mental illness (see Kessler \& Zhao's, 1999, study). ${ }^{1}$ Are all individuals without mental disorders leading equally productive and healthy lives, and are they leading more productive and healthier lives than the mentally ill? Answers to this question require investigation of the structural axiom of the complete health model, which is supported by several lines of thought and research.

First, many individuals otherwise free of mental disorder do not feel healthy or function well. Nearly half of adults receive mental health services annually because a mental health problem is inferred, meaning that there was no diagnosable disorder (Regier et al., 1993). Second, positive and negative affects form two correlated factors (Bradburn, 1969; Tellegen, Watson, \& Clark, 1999; Watson \& Tellegen, 1985). Thus, for example, individuals who may not feel sad-a defining feature of depression- do not necessarily experience high levels of happiness. Third, select measures of subjective well-being and common mental illnesses form distinct, correlated factors (Headey, Kelley, \& Wearing, 1993, focused on life satisfaction, happiness, anxiety, and depressive symptoms; Keyes \& Ryff, 2003, focused on psychological wellbeing and depressive symptoms). Thus, the structural axiom suggests that scholars and clinicians must take into account both mental illness and mental health, in which mental health is something positive.

\section{A Conception and Operationalization of Mental Health}

The Surgeon General defined mental health as ". . . a state of successful performance of mental function [italics added], resulting in productive activities, fulfilling relationships with people, and the ability to adapt to change and to cope with adversity" (U.S. Public Health Service, 1999, p. 4). Mental health is clearly something positive, but what exactly composes this positive state of mind? Keyes (2002) defined mental health as a syndrome of symptoms of hedonia and positive functioning, operationalized by measures of subjective well-being-individuals' perceptions and evaluations of their lives and the quality of their functioning in life.

Nearly half a century of research has yielded as many as 13 symptoms (i.e., measures) of mental health that, when factor analyzed, represent either the latent structure of hedonic wellbeing or eudaimonic well-being (Keyes, Shmotkin, \& Ryff, 2002; Keyes \& Waterman, 2003; McGregor \& Little, 1998; Ryan \& Deci, 2001; Waterman, 1993). Table 1 presents the proposed cluster of symptoms and diagnostic criteria for mental health (i.e., flourishing). It is noteworthy that, without intending it, subjective well-being research yielded clusters of mental health symptoms that mirror the cluster of symptoms used in the Diagnostic and Statistical Manual of Mental Disorders (4th ed., text rev.; DSMIV-TR; American Psychiatric Association, 2000) to diagnose major depressive episode (MDE). In the same way that depression requires symptoms of anhedonia, mental health is proposed to consist of symptoms of hedonia, or emotional vitality and positive feelings toward one's life. Moreover, in the same way that major depression consists of symptoms of malfunctioning, mental health is proposed to consist of symptoms of positive functioning.
The diagnosis of states of mental health was modeled after the $D S M-I I I-R$ approach to diagnosing MDE (Keyes, 2002). A diagnosis of depression is made when an individual reports at least one symptom from the anhedonia cluster and four or more symptoms of malfunctioning. Thus, to be diagnosed with MDE, individuals must exhibit at least five of nine possible symptoms, which is $55.6 \%$ or more of the total possible symptoms. Similarly, this article adopts the criteria outlined in Keyes's (2002) study, in which individuals must exhibit at least 7 of the possible 13 symptoms of subjective well-being, which is $53.8 \%$ or more of the total possible symptoms of mental health. Specifically, to be diagnosed as flourishing in life, individuals must exhibit high levels on one of the two scales of hedonic well-being and high levels on 6 of the 11 scales of positive functioning. To be diagnosed as languishing in life, individuals must exhibit low levels on one of the two scales of hedonic well-being and low levels on 6 of the 11 scales of positive functioning. Adults who are moderately mentally healthy do not fit the criteria for either flourishing or languishing in life. As with the diagnosis of major depression, symptoms of hedonia are essential for the diagnosis of mental health; individuals must exhibit a high level of satisfaction or a high level of positive affect.

In addition, the $D S M-I V-T R$ Axis V (i.e., global assessment of functioning [GAF] assessment) is a continuous variable approach that is proffered in this article as a second diagnostic approach for mental health. Here, the items and scales that measure each mental health cluster are summed together and coded into 10-point range categories. Unlike the categorical diagnosis, the continuous assessment of mental health does not mirror any specific DSM-III-R mental illness. Hedonic well-being obviously remains part of the assessment of mental health, but it is not considered an essential symptom to have a high level of mental health. Instead, high-level mental health requires individuals to report high levels on most (or all) measures of subjective well-being, whereas the categorical diagnosis of flourishing requires only high levels on over half of the measures. The continuous assessment of mental health, therefore, provides a more holistic assessment of mental health than the categorical diagnosis, and it is used here to assess whether results depend on the diagnosis or the assessment.

There also remains skepticism regarding the scientific and applied value of measuring and classifying individuals in terms of their mental health. According to Mechanic (1999), "Although the concept of positive mental health is one worth keeping in mind, it is not very helpful in classifying different persons, groups, or populations" (p. 2). Whether Mechanic's claim is warranted is an empirical question that has yet to be studied. Therefore, and as displayed in Figure 1, I also investigate the functioning axiom of the complete health model in this study. Complete mental health (i.e., the absence of mental illness and presence of flourishing) is more functional and adaptive than moderate mental health or pure languishing (i.e., absence of mental illness). In turn, pure languishing is as dysfunctional as an episode of pure mental illness (i.e., presence of mental illness but also the presence of moderate mental health or maybe even flourishing). Last, complete mental

\footnotetext{
${ }^{1}$ Data from the National Comorbidity Study indicate that one half of the economically viable population (i.e., ages 15-54 years) will remain free of mental illness over its lifetime and about $70 \%$ annually does not fit the $D S M-I V-T R$ criteria for most mental illnesses.
} 
Table 1

Categorical Diagnosis of Mental Health (i.e., Flourishing)

\begin{tabular}{|c|c|}
\hline Diagnostic criteria & Symptom description \\
\hline $\begin{array}{l}\text { Hedonia: requires high level on at least one } \\
\text { symptom scale (Symptoms } 1 \text { or } 2 \text { ) }\end{array}$ & $\begin{array}{l}\text { 1. Regularly cheerful, in good spirits, happy, calm and } \\
\text { peaceful, satisfied, and full of life (positive affect } \\
\text { past } 30 \text { days) } \\
\text { 2. Feels happy or satisfied with life overall or } \\
\text { domains of life (avowed happiness or avowed life } \\
\text { satisfaction) }^{\mathrm{a}}\end{array}$ \\
\hline $\begin{array}{l}\text { Positive functioning: requires high level on } \\
\text { six or more symptom scales (Symptoms 3-13) }\end{array}$ & $\begin{array}{l}\text { 3. Holds positive attitudes toward oneself and past life } \\
\text { and concedes and accepts varied aspects of self } \\
\text { (self-acceptance) } \\
\text { 4. Has positive attitude toward others while } \\
\text { acknowledging and accepting people's differences } \\
\text { and complexity (social acceptance) } \\
\text { 5. Shows insight into own potential, sense of } \\
\text { development, and open to new and challenging } \\
\text { experiences (personal growth) } \\
\text { 6. Believes that people, social groups, and society } \\
\text { have potential and can evolve or grow positively } \\
\text { (social actualization) } \\
\text { 7. Holds goals and beliefs that affirm sense of } \\
\text { direction in life and feels that life has a purpose } \\
\text { and meaning (purpose in life) } \\
\text { 8. Feels that one's life is useful to society and the } \\
\text { output of his or her own activities are valued by or } \\
\text { valuable to others (social contribution) } \\
\text { 9. Exhibits capability to manage complex } \\
\text { environment, and can choose or manage and mold } \\
\text { environments to suit needs (environmental mastery) } \\
\text { 10. Interested in society or social life; feels society and } \\
\text { culture are intelligible, somewhat logical, } \\
\text { predictable, and meaningful (social coherence) } \\
\text { 11. Exhibits self-direction that is often guided by his or } \\
\text { her own socially accepted and conventional internal } \\
\text { standards and resists unsavory social pressures } \\
\text { (autonomy) } \\
\text { 12. Has warm, satisfying, trusting personal relationships } \\
\text { and is capable of empathy and intimacy ( positive } \\
\text { relations with others) } \\
\text { 13. Has a sense of belonging to a community and } \\
\text { derives comfort and support from community } \\
\text { (social integration) }\end{array}$ \\
\hline
\end{tabular}

${ }^{a}$ Life domains may include employment and marriage or close interpersonal relationship (e.g., parenting).

illness (i.e., presence of mental illness and absence of mental health-languishing) should be more dysfunctional than a pure mental illness. These predictions may only apply to the most common mental disorders (e.g., anxiety and mood) rather than the less common but more severe psychotic disorders. Nonetheless, the functioning axiom predicts that within the realm of mental health, completely mentally healthy individuals will function bet-

\begin{tabular}{|ll} 
Mental \\
Illness and \\
Languishing
\end{tabular}$\quad \begin{aligned} & \text { Pure } \\
& \text { Mental } \\
& \text { Iliness }\end{aligned} \quad \begin{aligned} & \text { Pure } \\
& \text { Languishing }\end{aligned} \quad \begin{aligned} & \text { Moderately } \\
& \text { Mentally } \\
& \text { Healthy }\end{aligned}>\begin{aligned} & \text { Completely } \\
& \text { Mentally } \\
& \text { Healthy }\end{aligned}$

Figure 1. Predictions of psychosocial functioning from the complete state model of mental health. Signs are reversed for negative outcomes. Pure mental illness $=$ any 12-month mental disorder without languishing; pure languishing $=$ any languishing without any 12-month mental disorder. ter than moderately mentally healthy individuals, who in turn should function better than languishing individuals.

\section{Method}

\section{Sample}

Data are from the Midlife in the United States (MIDUS) survey conducted by the MacArthur Foundation's Research Network on Successful Midlife Development. The MIDUS is a national probability sample, drawn with random digit dialing procedures, that consisted of English-speaking, noninstitutionalized adults, age 25-74 years, who resided in the 48 contiguous states and whose household included at least one telephone. The first stage of the multistage sampling design selected households with equal probability via telephone numbers. Disproportionate stratified sampling was used at the second stage to select respondents. The sample was stratified by age and gender, with oversampling of men between the ages of 65 and 74 years. Working nonhousehold (e.g., business) numbers were eliminated by definition, and working numbers that were unsuccessfully contacted 10 times were also eliminated. 
The MIDUS survey complied with Institutional Review Board standards, and interviewers read a standard informed consent protocol at the beginning of the telephone interview. Adults who agreed to participate were administered a computer-assisted telephone interview that lasted 45 min on average and were then mailed two questionnaire booklets that required about $1.5 \mathrm{hr}$ on average to complete. All participants were offered $\$ 20$ and a copy of a final study monograph as incentives for participation. With a response rate of $70 \%$ for the telephone phase and a response rate of $87 \%$ for the self-administered questionnaire phase, the overall response rate was $61 \%$ with a sample size of 3,032 respondents. Field procedures lasted approximately 13 months and were begun in 1994 and concluded in 1995.

Descriptive analyses are based on the weighted sample to correct for unequal probabilities of household and within household respondent selection. The sample weight poststratifies the sample to match the proportions of adults according to age, gender, education, marital status, race, residence (i.e., metropolitan and nonmetropolitan), and region (northeast, midwest, south, and west) on the basis of the October 1995 Current Population Survey (see Keyes et al.'s, 2002, study for the demographic characteristics of the MIDUS sample). Findings were unchanged by whether the sample was weighted; all descriptive analyses present the findings based on the weighted sample. The sampling design involved some complexities that could introduce design effects that inflate standard error estimates. However, simulations with jackknife repeated replications (see Kish \& Frankel's, 1974, study) on an array of variables revealed very small standard error inflation of design-based estimates, eliminating the need to adjust statistical tests for design effects in these data.

\section{Measures}

Mental illness. The MIDUS used DSM-III-R (American Psychiatric Association, 1987) criteria to diagnose mental illness, which were operationalized by the Composite International Diagnostic Interview Short Form (CIDI-SF) scales (Kessler, Andrews, Mroczek, Ustun, \& Wittchen, 1998). Studies have shown that the CIDI-SF has excellent diagnostic sensitivity and diagnostic specificity as compared with diagnoses based on the full CIDI in the National Comorbidity Study (Kessler, DuPont, Berglund, \& Wittchen, 1999). During the telephone interview, the CIDI-SF was used to assess whether respondents exhibited symptoms indicative of (a) MDE, (b) generalized anxiety disorder, (c) panic disorder, and (d) alcohol dependence during the past 12 months (note that all diagnostic criteria used in this study conform to the criteria outlined in the DSM-IV-TR).

Mental health. As part of the self-administered questionnaire, respondents indicated how much of the time during the past 30 days-"all," "most," "some," "a little," or "none of the time"- - they felt six symptoms of positive affect. The positive affect symptoms were (a) cheerful, (b) in good spirits, (c) extremely happy, (d) calm and peaceful, (e) satisfied, and (f) full of life. The internal reliability of the positive affect scale was .91. Moreover, respondents were asked to "rate their life overall these days" on a scale ranging from 0 (worst possible life overall) to 10 (best possible life overall).

Respondents also completed Ryff's (1989) scales of psychological wellbeing and Keyes's (1998) scales of social well-being. The psychological well-being scales reflect how much individuals are thriving in their private, personal lives. The scales, with a representative item in parentheses, are as follows: self-acceptance ("I like most parts of my personality"), positive relations with others ("Maintaining close relationships has been difficult and frustrating for me"), personal growth ("For me, life has been a continual process of learning, changing, and growth"), purpose in life ("I sometimes feel as if I've done all there is to do in life"), environmental mastery ("I am good at managing the responsibilities of daily life"), and autonomy ("I tend to be influenced by people with strong opinions"). The measures of social well-being operationalize how much individuals see themselves thriving in their public, social life. The scales, with a representative item in parentheses, are as follows: social-acceptance ("People do not care about other peoples' problems"), social actualization ("Society is not improving for people like me"), social contribution ("My daily activities do not create anything worthwhile for my community"), social coherence ("I cannot make sense of what's going on in the world"), and social integration ("I feel close to other people in my community").

Each scale of positive functioning (i.e., psychological and social) consisted of three items with a relative balance of positive and negative items and were self-administered. Respondents indicated whether an item described how they functioned on a scale ranging from 1 (strongly agree) to 7 (strongly disagree). Negative items were reverse coded. The three-item scales of psychological well-being have shown modest internal consistency (Ryff \& Keyes, 1995), whereas the larger, 20-item scales have shown excellent internal consistency and construct validity (see Ryff's, 1989, study). Confirmatory factor analyses also confirmed the proposed sixfactor structure of psychological well-being (Ryff \& Keyes, 1995). The internal consistency of the combined 18 items of psychological well-being in this study was .81. Similarly, the three-item scales of social well-being have shown modest-to-excellent internal consistency, and the larger item scales of social well being have exhibited good internal consistency and construct validity (see Keyes's, 1998, study). Confirmatory factor analyses supported the proposed five-factor structure of social well-being (Keyes, 1998). The internal consistency of the combined items of social well-being in the current study was .81 . Table 2 presents the bivariate correlations and descriptive statistics of the continuous (i.e., symptom count) measures of mental disorder and the summed scale of each type of subjective well-being.

Table 2

Bivariate Correlations and Descriptive Statistics

\begin{tabular}{lcrrrrrr}
\hline Variable & 1 & 2 & 3 & 4 & 5 & 6 & 7 \\
\hline 1. No. depression symptoms & 1.00 & .33 & .32 & .07 & -.33 & -.26 & -.16 \\
2. No. generalized anxiety symptoms & & 1.00 & .26 & $.02^{\mathrm{a}}$ & -.19 & -.22 & -.15 \\
3. No. panic attack symptoms & & & 1.00 & .08 & -.22 & -.19 & -.14 \\
4. No. alcohol dependence symptoms & & & & 1.00 & -.15 & -.08 & $-.03^{\mathrm{a}}$ \\
5. Summed scale, emotional well-being & & & & & 1.00 & .54 & .36 \\
6. Summed scale, psychological well-being & & & & & & 1.00 & .53 \\
7. Summed scale, social well-being & & & & & & & 1.00 \\
$\quad$ Range & $0-7$ & $0-10$ & $0-6$ & $0-7$ & $1-15$ & $12-42$ & $5-35$ \\
$M$ & 0.84 & 0.21 & 0.37 & 0.53 & 11.00 & 32.90 & 22.10 \\
$S D$ & 2.00 & 1.10 & 1.10 & 1.20 & 2.20 & 4.80 & 4.70 \\
\end{tabular}

Note. Correlations are significant at $p<.001$ (two-tailed)

${ }^{\text {a }}$ Statistically nonsignificant. 
Before applying the proposed diagnostic criteria, I divided each scale of emotional, psychological, and social well-being by the number of constituent items, standardized, and I computed tertiles. The statistical tertile defines the threshold for high-level (i.e., upper tertile) and low-level (i.e., lower tertile) subjective well-being, because there are no other unambiguous thresholds. Thus, like mental disorder, mental health can be viewed as a deviation from usual functioning, which can be operationalized by the statistical average or by an ideal standard (e.g., Mechanic, 1999). In this study, the tertile operationalizes flourishing as above-average functioning and languishing as below-average functioning.

Psychosocial functioning. Respondents indicated whether their health limited them "a lot," "some," "a little," or "not at all" from doing any of nine instrumental activities of daily life. The activities included lifting and carrying groceries, bathing or dressing oneself, climbing several flights of stairs, bending (kneeling or stooping), walking more than 1 mile, walking several blocks, walking one block, performing vigorous activity (e.g., running, lifting heavy objects), and performing moderate activity (e.g., bowling or vacuuming). The internal consistency of the limitation of activity of daily living scale was .91 .

Respondents indicated the number of missed and cutback workdays during the past 30 days. Specifically, of the past 30 days, respondents were asked "How many days were you totally unable to go to work or carry out your normal household work activities because of your physical health or mental health?" Subsequently, of the past 30 days, and aside from those days they were totally unable to work, respondents were asked, "How many of the other days did you have to cut back on work or how much you got done because of your physical health or mental health?" Follow-up questions inquired whether the work cutbacks and lost days of work were due to physical health, to mental health, or to a combination of mental and physical health. In this study, I focused only on work cutbacks and lost days due to mental health.

Respondents also were asked whether they "agreed" or "disagreed" with the following statements: "I often feel helpless in dealing with the problems of life" and "There is little I can do to change the important things in my life." Analyses focused on the proportion that agreed with the helplessness statements. To measure goal formation, I asked respondents whether the statements, "I know what I want out of life" and "I find it helpful to set goals for the near future," described them "a lot," "some," "a little," or "not at all." Two statements measured respondents' resilience. First, "When faced with a bad situation, I do what I can to change it for the better." Second, "I find I usually learn something meaningful from a difficult situation." Respondents indicated whether each statement described them "a lot," "some," "a little," or "not at all." Last, intimacy was measured by asking respondents to indicate whether their (a) spouse or partner (or other family members) and (b) friends "really care(s) about them." Respondents indicated whether each statement described them "a lot," "some," "a little," or "not at all." In this study, I focused analyses on the proportion that said that the goal formation, resilience, and intimacy questions described their situation "a lot."

\section{Results}

Table 3 reports the indices of fit of confirmatory factor models that test different theories of the latent structure of the measures of mental health and mental illness. Three scales served as indicators of the latent construct of mental health: the summed scales that reflected emotional well-being (i.e., satisfaction plus positive affect), psychological well-being (i.e., six scales of psychological well-being summed together), and social well-being (i.e., the five scales of social well-being summed together). Four summary measures served as indicators of the latent construct of mental illness: the number of symptoms of MDE, generalized anxiety, panic disorder, and alcohol dependence. The independence model is a baseline in which there were as many latent constructs as measures of mental health and illness (i.e., each measure reflects an independent latent factor). The chi-square statistic and descriptive fit indices were very large, indicating that the theory of independence is untenable.

By comparison, and consistent with the psychiatric model of mental health, Model 2 posits that all measures are caused by a single, bipolar latent dimension. The chi-square statistic and descriptive fit indices were markedly improved for the single-factor model relative to the independence model. Moreover, the chisquare contrast of the independence and single-factor models revealed a highly statistically significant reduction of chi-square, suggesting that the single-factor (psychiatric) model was a more tenable model than the independence model. However, stemming from the complete state model of health, Model 3-which posits that the measures of mental health and mental illness reflect two distinct, but uncorrelated, unipolar factors-also had markedly improved fit indices. The chi-square contrast of the independence and two-factor (orthogonal) model revealed a highly statistically significant reduction of chi-square, suggesting that it too was a more tenable model than the independence model.

The final model fully tests the structural axiom of the complete health model, that is, measures of mental health and illnesses

Table 3

Maximum Likelihood Estimation of Confirmatory Factor Models of Theories of the Latent

Structure of Continuous Measures of Mental Health and DSM-III-R Mental Disorders

\begin{tabular}{lrcrrrrr}
\hline Latent structure model & \multicolumn{1}{c}{$\chi^{2}$} & $d f$ & AGFI & CN & RMSEA & AIC & $\begin{array}{r}\chi_{\text {difference }}^{2} \\
d f_{\text {difference }}\end{array}$ \\
\hline 1. Independence & $3,388.7$ & 21 & .60 & 25.5 & .22 & $3,402.7$ & \\
2. Single axis & 582.6 & 14 & .88 & 150.8 & .12 & 687.7 & $400.9_{1-2}{ }^{*}$ \\
3. Two axes, orthogonal & 557.3 & 14 & .91 & 157.7 & .11 & 543.6 & $404.5_{1-3}{ }^{*}$ \\
4. Two axes, oblique & 162.4 & 13 & .97 & 511.7 & .06 & 193.5 & $394.9_{3-4}{ }^{\mathrm{a}}$ \\
\hline
\end{tabular}

Note. $\quad \mathrm{N}=2,997$. Mental illness measures included measures of the number of symptoms of four mental disorders: panic disorder, major depressive episode, generalized anxiety, and alcohol dependence; mental health measures included the summed scales of emotional well-being, psychological well-being, and social well-being. AGFI $=$ adjusted goodness of fit index; $\mathrm{CN}=$ critical $N$; RMSEA = root-mean-square error of approximation; AIC $=$ Akaike information criterion .

${ }^{\text {a }}$ The correlation (phi) between latent factors is -.53 .

$* p<.001$. 
Table 4

Prevalence and Comorbidity of 12-month DSM-III-R Mental Disorders With Mental Health Diagnosis (Sample Weighted)

\begin{tabular}{|c|c|c|c|c|c|c|c|c|c|c|c|}
\hline \multirow[b]{3}{*}{ Mental disorder } & & \multicolumn{3}{|c|}{ Categorical diagnosis } & \multicolumn{6}{|c|}{ Continuous assessment } & \multirow[b]{2}{*}{ Total } \\
\hline & & $\begin{array}{c}\text { Mentally } \\
\text { unhealthy } \\
\text { (languishing) }\end{array}$ & $\begin{array}{l}\text { Moderately } \\
\text { mentally } \\
\text { healthy }\end{array}$ & $\begin{array}{c}\text { Mentally } \\
\text { healthy } \\
\text { (flourishing) }\end{array}$ & $0.0-9.9$ & $10.0-19.9$ & $20.0-29.9$ & $30.0-39.9$ & $40.0-49.9$ & $50.0-60.0^{\mathrm{a}}$ & \\
\hline & $\begin{array}{l}n \\
\%\end{array}$ & $\begin{array}{l}511 \\
16.9\end{array}$ & $\begin{array}{r}1,974 \\
\quad 65.1\end{array}$ & $\begin{array}{l}547 \\
18.0\end{array}$ & $\begin{array}{l}13 \\
0.4\end{array}$ & $\begin{array}{c}109 \\
3.7\end{array}$ & $\begin{array}{c}477 \\
16.2\end{array}$ & $\begin{array}{r}1,108 \\
37.5\end{array}$ & $\begin{array}{c}962 \\
32.6\end{array}$ & $\begin{array}{c}283 \\
9.6\end{array}$ & \\
\hline \multicolumn{12}{|c|}{ Major depressive episode } \\
\hline$n$ & & 143 & 254 & 26 & 9 & 49 & 11 & 169 & 74 & 12 & 422 \\
\hline$\%$ & & 28.0 & 13.4 & 4.8 & 69.2 & 45.0 & 23.3 & 15.3 & 7.7 & 4.2 & 14.1 \\
\hline \multicolumn{12}{|c|}{$\begin{array}{l}\text { Generalized anxiety } \\
\text { disorder }\end{array}$} \\
\hline$n$ & & 54 & 41 & 2 & 5 & 21 & 34 & 30 & 6 & 2 & 98 \\
\hline$\%$ & & 10.6 & 2.2 & 0.4 & 41.7 & 19.3 & 7.1 & 2.7 & 0.6 & 0.7 & 3.3 \\
\hline \multicolumn{12}{|l|}{ Panic disorder } \\
\hline$n$ & & 80 & 119 & 5 & 4 & 25 & 60 & 72 & 40 & 3 & 204 \\
\hline$\%$ & & 15.7 & 6.3 & 0.9 & 30.8 & 22.9 & 12.6 & 6.5 & 4.2 & 1.1 & 6.9 \\
\hline \multicolumn{12}{|c|}{ Alcohol dependence } \\
\hline$n$ & & 48 & 134 & 15 & 2 & 9 & 38 & 87 & 54 & 5 & 194 \\
\hline$\%$ & & 9.4 & 6.8 & 2.7 & 15.4 & 8.3 & 8.0 & 7.8 & 5.6 & 1.8 & 6.6 \\
\hline \multicolumn{12}{|l|}{ Comorbidity $^{\mathrm{b}}$} \\
\hline$n$ & & 84 & 107 & 4 & 7 & 32 & 56 & 71 & 24 & 3 & 193 \\
\hline$\%$ & & 16.4 & 5.4 & 0.7 & 53.8 & 29.4 & 11.7 & 6.4 & 2.5 & 1.1 & 6.5 \\
\hline
\end{tabular}

Note. For the separate tests of the association of each mental health diagnosis (categorical and also continuous) with each mental illness diagnosis, $p<$ .002 (two-tailed) for all chi-square tests.

${ }^{a}$ All separate scales of each type of subjective well-being were summed together to form an overall score, and the overall scores were recoded to reflect a total score ranging from 0 to the highest score, which was 60.8 ; because only three scores exceeded 60 , and not even by a full point, those three scores were top coded into the 50-60 category.

${ }^{\mathrm{b}}$ Two or more (maximum $\left.=4\right)$ mental disorders during the past 12 months.

constitute separate latent factors, and the two latent factors are correlated. The chi-square contrast of the two-factor (orthogonal) Model 3 and the two-factor (oblique) Model 4 revealed a highly statistically significant reduction of chi-square, suggesting that the correlated two-factor model was the most tenable model of the structure of mental health and illness. Moreover, the fit indices for Model 4 suggested that it was an excellent fitting model to these data. The adjusted goodness-of-fit index was .97 , the critical $N$ was twice as large as the recommended cutpoint of 200, and the root-mean-square error of approximation and Akaike information criterion were smaller than for Model 3. The correlation between the latent factor of mental illness and mental health was -.53 . The standardized loadings of all mental health indicators on their latent factor were .60 or higher, and the standardized loadings of the mental illness measures on their latent factor were .50 or higher, except for alcohol dependence, which was $.12 .^{2}$ In sum, data strongly support the structural axiom hypothesis; the theory that the measures of mental health and mental illness constitute separate, correlated axes provides the best fitting model to these data.

Table 4 reports the prevalence of mental health as diagnosed categorically and assessed continuously. Only $18 \%$ fit the categorical diagnosis of flourishing. Moreover, only $9.6 \%$ fit into the highest range of the continuous assessment of mental health (i.e., 50-60), which was the fourth most prevalent range of mental health scores. Rather, most Americans, roughly 6 in 10 according to the categorical diagnosis, were moderately mentally healthy. Similarly, the most prevalent range of mental health scores was the approximate midpoint of the continuous assessment (i.e., 30.039.9). Although few Americans were languishing-about $17 \%$ according to the categorical diagnosis-it is important to note that nearly as many Americans were mentally unhealthy (i.e., languishing) as were mentally healthy (i.e., flourishing). Similarly, although less than $1 \%$ fell into the lowest range of the continuous assessment (i.e., 0.0-9.9), a combined total of just over $20 \%$ fell below the approximate midpoint, with continuous scores at 29.9 or lower.

Table 4 also reports the association of the four $D S M-I I I-R$ mental disorders and their comorbidity with the mental health diagnoses. Whether I used the categorical diagnosis or continuous assessment, the pattern of results is unequivocal: Flourishing individuals were at the lowest risk of any of the four 12-month mental illnesses or their comorbidity. Conversely, and because causality may operate in the other direction, individuals with any of the four mental disorders were at a very low risk of flourishing. Moreover, the relationship of mental illness and mental health represents a gradient; the prevalence of each mental illness decreased as level of mental health increased. For example-and

\footnotetext{
2 The findings reported here include alcohol dependence as an indicator of mental illness because reestimation of the two-factor (oblique) model without alcohol dependence did not change any of the descriptive fit indices and only changed the latent factor correlation by a single point (i.e., $\phi=-.52)$
} 
focusing on the categorical diagnosis of mental health-28\% of languishing and $13 \%$ of moderately mentally healthy individuals (compared with $5 \%$ of flourishing adults) had MDE. Flourishing individuals were over 5 times less likely than languishers to have MDE. Flourishing individuals also were 23 times less likely than languishers to have had comorbid mental disorders over the 12month period.

Table 5 contains the cross-tabulation of whether individuals had any of the mental disorders by the categorical mental health diagnosis to obtain the estimates of the states of complete mental health. The prevalence of complete mental health was nearly $17.0 \%$, whereas just over $50.0 \%$ were moderately mentally healthy. Nearly $10.0 \%$ had a form of pure languishing, which is languishing without any of the four mental disorders. Pure languishers also reported an average of less than one symptom of any of the mental illnesses, suggesting it is not a subclinical form of any of the four mental disorders. Of the $22.9 \%$ of adults who had any of the four mental illnesses, 7.0\% were also languishing, whereas $15.9 \%$ had a pure form of mental illness, meaning this latter group had either moderate mental health or was flourishing.

The functioning axiom predicts that complete mental health is the summum bonum of psychosocial functioning, suggesting it is more adaptive than moderate mental health or pure languishing. Findings in Table 5 primarily support the functioning axiom of the complete mental health model. Occupational and psychosocial malfunctioning was lowest, whereas positive functioning was greatest, among adults with complete mental health. Health limitations of activities of daily living, any half-day cutback and any loss of a day of work, and perceived helplessness were least likely among adults with complete mental health. Moreover, goals, re-

Table 5

Psychosocial Functioning by Categorical Diagnosis of Complete Mental Health (Sample Weighted)

\begin{tabular}{|c|c|c|c|c|c|c|}
\hline & & $\begin{array}{l}\text { Mental illness } \\
\text { and languishing }\end{array}$ & $\begin{array}{l}\text { Pure mental } \\
\text { illness }\end{array}$ & $\begin{array}{c}\text { Pure } \\
\text { languishing }\end{array}$ & $\begin{array}{l}\text { Moderately } \\
\text { mentally healthy }\end{array}$ & $\begin{array}{l}\text { Completely } \\
\text { mentally healthy }\end{array}$ \\
\hline & $n$ & 214 & 484 & 297 & 1,535 & 503 \\
\hline & & 1.0 & 15.9 & 9.8 & & \\
\hline \multicolumn{7}{|l|}{ Health limits—any of nine } \\
\hline \multicolumn{7}{|c|}{ Activities of daily living (a lot) } \\
\hline$n$ & & 73 & 128 & 98 & 349 & 61 \\
\hline$\%$ & & 34.3 & 26.4 & 33.0 & 22.7 & 12.1 \\
\hline \multicolumn{7}{|c|}{ Any work cutback during past 30 days } \\
\hline$n$ & & 69 & 104 & 32 & 106 & 17 \\
\hline$\%$ & & 34.5 & 22.3 & 11.3 & 7.1 & 3.4 \\
\hline \multicolumn{7}{|c|}{ Any lost workday during Past 30 days } \\
\hline$n$ & & 49 & 63 & 22 & 89 & 19 \\
\hline$\%$ & & 23.2 & 13.2 & 7.7 & 5.8 & 3.8 \\
\hline \multicolumn{7}{|l|}{ Helplessness } \\
\hline \multicolumn{7}{|c|}{ Feel helpless dealing with life's problems } \\
\hline$n$ & & 172 & 161 & 190 & 383 & 27 \\
\hline$\%$ & & 80.4 & 34.0 & 64.0 & 25.4 & 5.4 \\
\hline \multicolumn{7}{|c|}{ Cannot change important things in life } \\
\hline$n$ & & 99 & 96 & 129 & 381 & 42 \\
\hline$\%$ & & 46.7 & 20.2 & 43.6 & 25.4 & 8.5 \\
\hline \multicolumn{7}{|l|}{ Goals } \\
\hline \multicolumn{7}{|c|}{ Knows what wants out of life } \\
\hline$n$ & & 52 & 195 & 60 & 599 & 342 \\
\hline$\%$ & & 24.3 & 40.7 & 20.3 & 39.7 & 68.0 \\
\hline \multicolumn{7}{|c|}{ Finds it helpful to set goal for near future } \\
\hline$n$ & & 31 & 163 & 36 & 467 & 267 \\
\hline$\%$ & & 14.5 & 34.0 & 12.1 & 30.8 & 53.4 \\
\hline \multicolumn{7}{|l|}{ Resilience } \\
\hline \multicolumn{7}{|c|}{ Changes bad situations for better } \\
\hline$n$ & & 58 & 272 & 73 & 855 & 397 \\
\hline$\%$ & & 27.2 & 56.8 & 25.0 & 56.5 & 79.2 \\
\hline \multicolumn{7}{|c|}{ Learns from difficult situations } \\
\hline$n$ & & 70 & 284 & 92 & 762 & 346 \\
\hline$\%$ & & 32.7 & 59.5 & 31.1 & 50.5 & 69.8 \\
\hline \multicolumn{7}{|l|}{ Intimacy } \\
\hline \multicolumn{7}{|c|}{$\begin{array}{l}\text { Feels really cared for by spouse, partner, } \\
\text { or family }\end{array}$} \\
\hline$n$ & & 157 & 422 & 208 & 1,374 & 486 \\
\hline$\%$ & & 73.4 & 87.4 & 70.0 & 89.5 & 96.8 \\
\hline \multicolumn{7}{|c|}{ Feels really cared for by a friend } \\
\hline$n$ & & 58 & 247 & 53 & 729 & 336 \\
\hline$\%$ & & 27.2 & 51.8 & 18.1 & 48.5 & 67.3 \\
\hline
\end{tabular}

Note. For the separate tests of the association of the mental health diagnosis with each psychosocial functioning variable, $p<.001$ (two-tailed) for all chi-square tests. 
silience, and intimacy were greatest among adults with complete mental health. Indeed, completely mentally healthy adults generally functioned better than moderately mentally healthy adults; in turn, moderately mentally healthy adults functioned better than adults with pure languishing.

In contrast, occupational and psychosocial malfunctioning was greatest, whereas positive functioning was lowest, among adults with a 12-month mental illness on top of languishing. Health limitations of activities of daily living, any half-day cutback and any loss of an entire day of work, and perceived helplessness were greatest among adults with a mental illness as well as languishing. Goals, resilience, and intimacy also were lowest among adults who had a mental illness in addition to languishing, who, as predicted, functioned worse than adults with a pure mental illness.

The contrast in functioning between pure languishing and pure mental illnesses generally supports the functioning axiom. In 2 of the 11 indices, individuals with a pure mental illness functioned worse than individuals with pure languishing. Namely, a higher proportion of adults with pure mental illness (compared with pure languishing individuals) had more work cutbacks or lost more days of work. In 9 of the 11 indices, pure languishing was more dysfunctional than pure mental illness. For example, one third of pure languishers, compared with just over one quarter of individuals with pure mental illness, reported any health limitations of daily activities. Twice as many adults with pure mental illness (43\%) as adults with pure languishing $(21 \%)$ said that "knowing what they want out of life" described them a lot. Twice as many adults with pure mental illness (33\%) as adults with pure languishing $(15 \%)$ said that "it is helpful to set goals for the near future" described their situation a lot. Twice as many adults with pure mental illness (59\%) as adults with pure languishing (26\%) said that, "When faced with a bad situation, I do what I can to change it for the better" described them a lot. Nearly 3 times as many adults with pure mental illness (54\%) as with pure languishing $(18 \%)$ said that a "friend that really cares about them" described their situation a lot.

In sum, completely mentally healthy adults exhibited the fewest health limitations of daily activities, little or no work cutbacks or missed workdays, and high levels of psychosocial functioning. Complete mental health was the summum bonum of functioning, better than the relative absence of mental health - that is, moderate mental health and, especially, pure languishing. In turn, languishing was as bad as, and sometimes worse than, the presence of a pure mental illness. Last, complete mental illness - that is, the absence of mental health qua languishing and the presence of a mental disorder-was most dysfunctional, even more dysfunctional than a pure mental illness, at least as measured by some indicators.

\section{Discussion}

Mental illnesses such as MDE are a societal burden and are projected to become more prevalent and burdensome by the year 2020 (Murray \& Lopez, 1996). As such, there is little skepticism about the societal value of greater support for mental illness research. Rather than expand the scope of basic and applied research to include mental health (Gladis, Gosch, Dishuk, \& CritsChristoph, 1999), treatment and prevention of mental illness appear at first glance to be more urgent public health issues. How- ever, arguments for or against the study of positive or complete mental health are based on untested assumptions, two of which were investigated in this article.

First, mental health is presumed to be the opposite of mental illness; thus, the absence of mental illness equals the presence of mental health. Under this assumption, if society can effectively treat mental illness, then more individuals will become mentally healthy. The current study confirms empirically that mental health and mental illness are not opposite ends of a single continuum; rather, they constitute distinct but correlated axes that suggest that mental health should be viewed as a complete state. ${ }^{3}$ Thus, the absence of mental illness does not equal the presence of mental health. The structure of mental health as distinct from mental illness was implied by the introduction of Axis V (Luborsky, 1962) and the GAF scale to measure Axis V (Endicott, Spitzer, Fleiss, \& Cohen, 1976). However, Axis V remains underused relative to other $D S M-I V-T R$ axes, perhaps because the GAF exhibits relatively poor reliability and validity (Goldman, Skodol, \& Lave, 1992; Roy-Byrne, Dagadakis, Unutzer, \& Ries, 1996), and psychologists and psychiatrist rate its usefulness as very low (Frazee, Chicota, Templer, \& Arikawa, 2003).

Second, it is commonly assumed that classifying and monitoring the mental health status of individuals, groups, or populations is worthless. Individuals free of mental illness are assumed to be homogenous, functioning about the same and markedly better than mentally ill individuals. However, the diagnosis and measurement of mental health-however crude and preliminary some may think of the scheme presented here-has provided some invaluable information. First, relatively few adults (i.e., about 2 in 10) who were free of any of the four 12-month mental disorders could be classified as flourishing or completely mentally healthy. Almost as many adults were mentally unhealthy (i.e., languishing) as were mentally healthy (i.e., flourishing), and most adults were moderately mentally healthy. Second, diagnoses less than flourishing were associated with greater levels of dysfunctions in terms of work reductions, health limitations, and psychosocial functioning. Moreover, pure languishing was as dysfunctional (sometimes more) than pure mental illness (although the pure mental illness was associated with greater work problems). Mental illness when combined with languishing was markedly worse than a pure form of mental illness.

In addition, a recent study confirmed the hypothesis that the complete mental health diagnostic states were independent risk factors for cardiovascular disease (CVD; Keyes, 2004). In this study, I focused on the combination of the categorical diagnosis of mental health with MDE, because the latter has been shown to be a risk factor for heart and arterial diseases. The unadjusted prevalence of any CVD was $8 \%$ among completely mentally healthy adults, compared with $12 \%$ of adults with moderate mental health, $12 \%$ of adults with pure languishing, and $13 \%$ of adults with pure depression. Among adults who were languishing and had an episode of major depression, the prevalence of any CVD was $19 \%$. In multivariate analyses, completely mentally healthy adults had the

\footnotetext{
${ }^{3}$ The latent factors of mental health and mental illness correlated at -.53 , indicating that one quarter of variance between common measures of mental illness and mental health (i.e., subjective well-being) is shared variance.
} 
lowest risk for CVD. Anything less than complete mental healthespecially for postmenopausal women (for reasons hypothesized and explained in the full study report) - translated into elevated risk for CVD that was comparable with the risk associated with the known risk factors of diabetes, smoking, and lack of exercise.

There are several potential limitations to the current study. First, the MIDUS may not provide the most rigorous test of the structural axiom. Only four mental disorders were measured, and future research should include a wider assessment of mental disorders to fully investigate the structural axiom. Second, the subjective wellbeing scales are self-report measures and possibly reflect a bias toward westernized cultures and developed nations. Future research should include reports on the target's well-being from others (e.g., experts or family) and investigate whether the structure of subjective well-being (i.e., hedonia and eudaimonia), and dimensions therein, are replicated in other cultures. The sparse amount of comparative research in this area suggests that the structure of subjective well-being is likely to be the same, although the number and kind of eudaimonic dimensions is likely to vary by country (see Keyes \& Ryff's, 2003, study).

Third, the proposed diagnostic criteria and the validity of the diagnoses require further work. This study and previous research (Keyes, 2002) adopted a combination of statistical (e.g., tertile cutpoints) and rational (e.g., use of DSM-IV-TR number of symptoms to meet condition) diagnostic criteria. Although this study suggests that few adults are flourishing, changes in the diagnostic criteria would obviously change the point prevalence estimates and some conclusions. It also remains an empirical question whether a categorical taxon or a continuum best represents the latent structure of mental health as measured in this study. Future research should also explore additional criteria of mental health (e.g., a duration criterion) and alternative models of mental health as well as investigate the construct validity of any diagnoses against expert evaluations. $^{4}$

Findings also suggest directions for future research regarding the causal nexus of states of mental health with mental disorders. In particular, is languishing a diathesis for, and is flourishing a protective factor against, the onset and recurrence of mental illness? Conceptually, one can think of mental health as the continuum at the top of the cliff where most individuals reside. Flourishing individuals are at the healthiest and therefore farthest distance from the edge of this cliff; languishing places individuals very near the edge of the cliff. Hence, languishing may act as a diathesis that is activated by stressors that push individuals off the cliff and into mental illness.

Last, findings of the association of complete mental health with low helplessness and high goals, resilience, and intimacy suggests that extant talk therapies may be useful for promoting flourishing as well as treating mental illness. Prominent theories of the etiology, and therefore, treatment of depression have focused on cognitive-behavioral processes (e.g., Hollon, Thase, \& Markowitz, 2002). That is, mental illnesses such as depression result from either or both distorted thought and behavioral patterns or the inability to form and maintain positive interpersonal attachments. Years of research on learned helplessness (Seligman, 1975) has consistently shown that perceptions of one's helplessness and inability to change bad situations lead to distress and depression, whereas framing of life in terms of goals is associated with high levels of subjective well-being (Emmons, 2003). Research on resilience has shown that mental health depends on an individual's ability to mentally cope with, transform, and find meaningful lessons from the stressors and life's challenges (Ryff \& Singer, 2003). Last, a plethora of studies have indicated that interpersonal relationships that satisfy needs for belongingness and succor are instrumental to mental health (Harlow, 1958; Reis \& Gable, 2003).

In sum, mental health has been studied for too long as merely the absence of mental illness. It is time to heed the advice of the historic Joint Commission on Mental Illness and Health (see Gurin, Veroff, \& Feld, 1960; Jahoda, 1958), which recommended the study and promotion of mental health as well as the study and treatment of mental illness. Mental health is clearly something positive, and anything less than flourishing appears to fall short of healthy functioning in life.

\footnotetext{
${ }^{4}$ It is unclear who would be the most expert judge of another person's mental health, namely whether it would be a psychiatrist, psychotherapist, a long-term companion, a teacher or coach, or someone else.
}

\section{References}

American Psychiatric Association. (1987). Diagnostic and statistical manual of mental disorders (3rd ed., rev.). Washington, DC: Author.

American Psychiatric Association. (2000). Diagnostic and statistical manual of mental disorders (4th ed., text rev.). Washington, DC: Author.

Bradburn, N. M. (1969). The structure of psychological well-being. Chicago: Aldine.

Emmons, R. A. (2003). Personal goals, life meaning, and virtue: Well springs of a positive life. In C. L. M. Keyes \& J. Haidt (Eds.), Flourishing: Positive psychology and the life well-lived (pp. 105-128). Washington, DC: American Psychological Association.

Endicott, J., Spitzer, R. L., Fleiss, J. L., \& Cohen, J. (1976). The Global Assessment Scale: A procedure for measuring overall severity of psychiatric disturbance. Archives of General Psychiatry, 33, 766-771.

Frazee, J. C., Chicota, C. L., Templer, D. I., \& Arikawa, H. (2003). The usefulness of the Axis $\mathrm{V}$ diagnosis: Opinions of health care professionals. Journal of Nervous and Mental Disease, 191, 692-694.

Garrison, C. Z., Schluchter, M. D., Schoenbach, V. J., \& Kaplan, B. K. (1989). Epidemiology of depressive symptoms in young adolescents. Journal of the American Academy of Child and Adolescent Psychiatry, 28, 343-351.

Gladis, M. M., Gosch, E. A., Dishuk, N. M., \& Crits-Christoph, P. (1999). Quality of life: Expanding the scope of clinical significance. Journal of Consulting and Clinical Psychology, 67, 320-331.

Goldman, H. H., Skodol, A. E., \& Lave, T. R. (1992). Revising Axis V for $D S M-I V$ : A review of measures of social functioning. American Journal of Psychiatry, 149, 1148-1156.

Greenberg, P. E., Stiglin, L. E., Finkelstein, S. N., \& Berndt, E. R. (1993). The economic burden of depression in 1990. Journal of Clinical Psychiatry, 54, 405-418.

Gurin, G., Veroff, J., \& Feld, S. (1960). Americans view their mental health. New York: Basic Books.

Harlow, H. (1958). The nature of love. American Psychologist, 13, 573685 .

Headey, B. W., Kelley, J., \& Wearing, A. J. (1993). Dimensions of mental health: Life satisfaction, positive affect, anxiety, and depression. Social Indicators Research, 29, 63-82.

Hollon, S. D., Thase, M. E., \& Markowitz, J. C. (2002). Treatment and prevention of depression. Psychological Science in the Public Interest, 2, $39-76$.

Jahoda, M. (1958). Current concepts of positive mental health. New York: Basic Books. 
Kessler, R. C., Andrews, G., Mroczek, D., Ustun, B., \& Wittchen, H.-U. (1998). The World Health Organization Composite International Diagnostic Interview Short Form (CIDI-SF). International Journal of Methods in Psychiatric Research, 7, 171-185.

Kessler, R. C., DuPont, R. L., Berglund, P., \& Wittchen, H.-U. (1999). Impairment in pure and comorbid generalized anxiety disorder and major depression at 12 months in two national surveys. American Journal of Psychiatry, 156, 1915-1923.

Kessler, R. C., McGonagle, K. A., Zhao, S., Nelson, C. B., Hughes, M., Eshleman, S., et al. (1994). Lifetime and 12-month prevalence of DSM$I I I-R$ psychiatric disorders in the United States: Results from the National Comorbidity Survey. Archives of General Psychiatry, 51, 8-19.

Kessler, R. C., \& Zhao, S. (1999). The prevalence of mental illness. In A. V. Horwitz \& T. L. Scheid (Eds.), A handbook for the study of mental health: Social contexts, theories, and systems (pp. 58-78). New York: Cambridge University Press.

Keyes, C. L. M. (1998). Social well-being. Social Psychology Quarterly, 61, 121-140.

Keyes, C. L. M. (2002). The mental health continuum: From languishing to flourishing in life. Journal of Health and Social Behavior, 43, 207222

Keyes, C. L. M. (2003a). Complete mental health: An agenda for the 21st century. In C. L. M. Keyes \& J. Haidt (Eds.), Flourishing: Positive Psychology and the life well-lived (pp. 293-312). Washington, DC: American Psychological Association.

Keyes, C. L. M. (2003b). Promoting a life worth living: Human development from the vantage points of mental illness and mental health. In R. M. Lerner, F. Jacobs, \& D. Wertlieb (Eds.), Promoting positive child, adolescent, and family development: A handbook of program and policy innovations (Vol. 4, pp. 257-274). Thousand Oaks, CA: Sage.

Keyes, C. L. M. (2004). The nexus of cardiovascular disease and depression revisited: The complete mental health perspective and the moderating role of age and gender. Aging and Mental Health, 8, 266-274.

Keyes, C. L. M., \& Lopez, S. J. (2002). Toward a science of mental health: Positive directions in diagnosis and interventions. In C. R. Snyder \& S. J. Lopez (Eds.), Handbook of positive psychology (pp. 45-59). New York: Oxford University Press.

Keyes, C. L. M., \& Ryff, C. D. (2003). Somatization and mental health: A comparative study of the idiom of distress hypothesis. Social Science and Medicine, 57, 1833-1845.

Keyes, C. L. M., Shmotkin, D., \& Ryff, C. D. (2002). Optimizing wellbeing: The empirical encounter of two traditions. Journal of Personality and Social Psychology, 82, 1007-1022.

Keyes, C. L. M., \& Waterman, M. B. (2003). Dimensions of well-being and mental health in adulthood. In M. Bornstein, L. Davidson, C. L. M. Keyes, \& K. Moore (Eds.), Well-being: Positive development throughout the life course (pp. 477-497). Mahwah, NJ: Erlbaum.

Kish, L., \& Frankel, M. R. (1974). Inference from complex samples. Journal of the Royal Statistical Society, 36, 1-37.

Luborsky, L. (1962). Clinicians' judgments of mental health. Archives of General Psychiatry, 7, 407-417.

McGregor, I., \& Little, B. R. (1998). Personal projects, happiness, and meaning: On doing well and being yourself. Journal of Personality and Social Psychology, 74, 494-512.

Mechanic, D. (1999). Mental health and social policy: The emergence of managed care. Needham Heights, MA: Allyn \& Bacon.
Murray, C. J. L., \& Lopez, A. D. (Eds.). (1996). The global burden of disease: A comprehensive assessment of mortality and disability from diseases, injuries, and risk factors in 1990 and projected to 2020. Cambridge, MA: Harvard School of Public Health.

Regier, D. A., Narrow, W. E., Rae, D. S., Manderscheid, R. W., Locke, B. Z., \& Goodwin, F. K. (1993). The de facto U.S. mental and addictive disorders service system: Epidemiologic catchment area prospective 1 -year prevalence rates of disorders and services. Archives of General Psychiatry, 50, 85-94.

Reis, H. T., \& Gable, S. L. (2003). Toward a positive psychology of relationships. In C. L. M. Keyes \& J. Haidt (Eds.), Flourishing: Positive psychology and the life well-lived (pp. 129-159). Washington, DC: American Psychological Association.

Roy-Byrne, P., Dagadakis, C., Unutzer, J., \& Ries, R. (1996). Evidence for limited validity of the revised global assessment of functioning scale. Psychiatric Services, 47, 864-866.

Ryan, R. M., \& Deci, E. L. (2001). On happiness and human potentials: A review of research on hedonic and eudaimonic well-being. Annual Review of Psychology, 52, 141-166.

Ryff, C. D. (1989). Happiness is everything, or is it? Explorations on the meaning of psychological well-being. Journal of Personality and Social Psychology, 57, 1069-1081.

Ryff, C. D., \& Keyes, C. L. M. (1995). The structure of psychological well-being revisited. Journal of Personality and Social Psychology, 69, 719-727.

Ryff, C. D., \& Singer, B. (1998). Human health: New directions for the next millennium. Psychological Inquiry, 9, 69-85.

Ryff, C. D., \& Singer, B. (2003). Flourishing under fire: Resilience as a prototype of challenged thriving. In C. L. M. Keyes \& J. Haidt (Eds.), Flourishing: Positive psychology and the life well-lived (pp. 15-36). Washington, DC: American Psychological Association.

Sartorius, N. (2001). The economic and social burden of depression. Journal of Clinical Psychiatry, 62, 8-11.

Seligman, M. E. P. (1975). Helplessness: On depression, development, and death. San Francisco: Freeman.

Sigerist, H. E. (1941). Medicine and human welfare. New Haven, CT: Yale University Press.

Smith, M. B. (1959). Research strategies toward a conception of positive mental health. American Psychologist, 14, 673-681.

Tellegen, A., Watson, D., \& Clark, L. A. (1999). On the dimensional and hierarchical structure of affect. Psychological Science, 10, 297-303.

U.S. Public Health Service. (1998). Suicide: A report of the Surgeon General. Rockville, MD: Author.

U.S. Public Health Service. (1999). Mental health: A report of the Surgeon General. Rockville, MD: Author.

Waterman, A. S. (1993). Two conceptions of happiness: Contrasts of personal expressiveness (eudaimonia) and hedonic enjoyment. Journal of Personality and Social Psychology, 64, 678-691.

Watson, D., \& Tellegen, A. (1985). Toward a consensual structure of mood. Psychological Bulletin, 98, 219-235.

World Health Organization. (1948). World Health Organization Constitution. In Basic Documents. Geneva, Switzerland: Author.

Received February 11, 2004

Revision received November 6, 2004 Accepted November 10, 2004 